\title{
MODELING EXPRESSING ON DEMONSTRATING
}

\author{
MAURA TUMULTY \\ COLGATE UNIVERSITY
}

ABSTRACT: We can increase our understanding of expression by considering an analogy to demonstrative reference. The connections between a demonstrative phrase and its referent, in a case of fully successful communication with that phrase, are analogous to the connections between an expressible state and the behavior that expresses it. The connections in each case serve to maintain a certain status for the connected elements: as actions of persons; or as objects, events, or states significant to persons. The analogy to demonstrative reference helps show that a positive account of expression can make conceptual connections between expressed states and expressive behaviors without courting reductive behaviorism. A general account of expression as marked by these connections is compared to accounts of expression offered by Dorit Bar-On and Mitchell Green. Bar-On's account turns out to be compatible with the account proposed here, once some of its consequences are fully appreciated. Green's account rules out, as not expressive, some behaviors like crouching (in fear) that intuitively seem expressive. When Green's account is altered to allow such behaviors back in, the resulting account also fits the one proposed.

\section{INTRODUCTION}

\section{$\mathbf{T}$}

he notion of expression is often characterized negatively. For example, expressions of emotion might be contrasted with descriptions of emotion. We might indicate the expressive character of a gesture, such as catching hold of a child's hand, by denying that it was performed as a means to an end. The hand-holding, we might say, expresses affection rather than ensuring safe passage across a street. Making such contrasts emphasizes the especially tight connections between the 
behaviors and states related by expression. But it doesn't fully illuminate the nature of those connections.

A negative characterization of the expressive connection can be completely effective when the concept of expression is deployed to illuminate something else. Michael Dummett, for example, opposes the expressive relation between language and thought to the relation that would hold if language were merely a code for thought. He gives a careful exposition of what he means by a 'mere code,' and makes the intuitive notion of expression on which he relies more specific only by contrast with it. David Finkelstein relies on, but does not analyze, a notion of expression in distinguishing between conscious and unconscious states of mind. And Dorit Bar-On relies on a notion of expression to give an account of the distinctive properties of avowals. ${ }^{1}$ Bar-On is especially clear that her characterization of expressive relations is negative. She explores a positive characterization of expressive behavior as sufficient to show the states it expresses. But she argues that her account of avowals doesn't depend on the ultimate success of that positive characterization. What matters is only the truth of her negative characterization. Bar-On argues that expressive relations are not mediated by judgments in which an agent explicitly identifies either the states expressed or the person whose states they are. ${ }^{2}$ That is, when "My head aches" expresses my pain, my basis for making the claim includes neither any judgment of the form, "Someone has a headache, and $I$ am that person" nor any judgment of the form, "My head feels someway, and that way is achy."

Negative accounts of expression can be used to accomplish a great deal. And positive accounts face real dangers. A positive account that emphasized the distinctive and significant character of expressive ties might make them simply mysterious. ${ }^{3}$ On the other hand, a positive account that carefully avoided mystery might be suspected of driving toward behaviorist reductionism. Keeping expressive relations interesting but non-mysterious might require tying expressed states very closely to their expressings. If the ties are very close, the states could turn out to be nothing but dispositions to those expressings. Unless those dispositions include dispositions to be in cognitive or affective states, we will have reduced expressible mental states to (purely) behavioral dispositions. And if that happened, we wouldn't have any reason to continue calling such behavior 'expressive.' The behavior wouldn't bring anything else out.$^{4}$

Nevertheless, our intuitive judgments about what counts as expressive are strong, and often uncontroversial. So we should be able to sketch a positive account of what makes a relation expressive. This sketch would codify our classifications of some, but not all, of our behavior as expressive, after we've reflected on which of those classifications are appropriate. Deciding which pre-theoretical classifications need revision, and which are genuine counter-examples to a developing sketch, is complicated. While developing such a sketch is an exercise in conceptual analysis, some of those decisions might very well turn on empirical questions. ${ }^{5}$ This paper identifies features a positive account of expression should have, if it is to resonate 
with our reasons for caring about expressivity in the first place. It argues that an account with such features would be neither mysterious nor an invitation to behaviorist reductionism. We can take seriously our sense that we engage immediately and deeply with one another in our expressive behavior without falling into either of those traps.

Both the identification of the features, and the argument that they lead neither to mystification nor reductionism, proceed by analogy. The analogue is an account of the ties between topic and speech in some communication that employs demonstratives. In both cases, there are tight links between aspects of a total package (reference, or expression). The links serve to preserve the status of the items in the package as actions of persons or objects, events, or states significant to persons. The links keep accounts of individuals performing those actions, or being in those states, at the person level of explanation. Persons are agents capable of intentional action, who are usually intelligible as rationally motivated. And at the person level of explanation, they are in view as our objects of concern. ${ }^{6}$ Weeping in grief, like saying, "I can't believe she's gone" after the death of a loved one, should be understood at the person level. (It need not be understood as an intended action.) This will be argued as the details of the analogy are worked out.

I discuss the referential case first, and show that the links appealed to in this account of it are neither mysterious nor reductively behaviorist. I then explain which features of the referential case have analogues in the expressive case. In evaluating the resultant sketch of expressive relations, I first compare it to Bar-On's treatment of conceptual connections between expressed states and expressive behavior. The comparison enables me to show that a positive account of expression can insist on conceptual connections among the aspects of an expressive whole without courting behaviorism. Finally, I consider Mitchell Green's positive account of expression, which requires that expressive behavior be designed to show what it expresses. I argue that his account wrongly excludes some behaviors (such as crouching) that show emotions (such as fear). Altering his account to justify treating these behaviors as expressive would bring it in line with the sketch this paper proposes. I conclude by noting that, if we accept this sketch, we'd have an explanation for why accounts of expression and accounts of first-personal self-awareness often draw on one another.

\section{DEMONSTRATIVE REFERENCE ${ }^{7}$}

\section{A. AN INTUITIVE PICTURE}

When I say to a friend at a playground, "That girl looks ill," the status of my utterance as fully understandable depends on the perceptible girl. (The relevant notion of 'fully understandable' is explained below.) But both the utterance and the girl are perfectly concrete. Neither is inner, as (say) my sorrow is (or may seem to be) inner. The notions 'being understandable' and 'being perceived' are not necessarily easy to unpack. But neither a failure to perceive, nor a consequent failure to 
understand, is especially mysterious. My friend will want to perceive the relevant girl. She will take herself to still have a job to do so long as she doesn't yet know which girl is in question. That's true even if she is aware that I intend to be speaking about a particular girl, and am telling her, of that girl, that she is ill.

There is a difference between being able to characterize a speaker as attempting to inform us about some topic, and understanding the speaker in understanding what she said. And there are conversational conventions that suggest we regularly operate with a pre-theoretic recognition of that difference. The conventions are more obvious when they are being violated. For example, I sometimes fake compliance with them. That is, I'll say, "Yes, of course" to a question like, "Do you remember that house we saw the day your sister graduated?" because I just want my husband to finish his story. Needless to say, when I do this, I don't want to be found out. And I'm quite annoyed when I realize someone is doing this to me. ${ }^{8}$

The difference between successful and unsuccessful communication with demonstratives doesn't seem mysterious. If my friend speaks English and perceives the right girl, she fully understands me; if not, not. There is a tight connection between my utterance and the girl, but noting this doesn't (for example) appear to commit us to any but a naturalist account of the communicative exchange. We can investigate the connections between demonstrative and referent—-between 'that girl' and the girl herself - to identify features of this kind of tight connection. Drawing the analogies to the connections between expressings and what they express will give us a blueprint for a positive account of expressive connections. The blueprint itself, if not its further development, will be free of overt appeals to the notion of expression. That will help alleviate the worry that the only tight connections are mysterious ones.

\section{B. CONNECTIONS BETWEEN WORD AND WORLD}

In central cases, a phrase like 'that girl' has a referent and expresses a sense. ${ }^{9}$ The sense is grasped by the speaker and by anyone who fully understands her utterance. The relevant notion of understanding requires more of a hearer than that she can identify the sentence-type used, and imagine possible speech-acts a speaker might reasonably wish to use it to perform. Of course, imagining what another person was trying to communicate requires one to have appreciated a good bit about the words he or she uttered. There is certainly a sense of 'understand' that can simply track that level of appreciation. My target is not understanding in that sense, but rather cases of what I will call full understanding: cases of full communicative success, as could occur between my friend and me at the playground if she knows to which girl I refer. The connections among the elements in that kind of case are my focus. ${ }^{10}$ (While I continue to use 'full understanding,' other qualifications to this effect will be dropped in what follows.) I'll list them and then characterize the second and third connections more fully.

(1) Reference: As used by the speaker, the phrase 'that girl' refers to Jane. 
(2) Referent-dependence: A hearer fully understands the utterance containing the phrase only if she perceives Jane. ${ }^{11}$ So for the utterance to be fully understandable, the phrase 'that girl' must in fact have a referent it would be possible for a hearer to perceive. ${ }^{12}$ So the status of 'that girl' as a referring phrase in this context depends on the existence of that referent-Jane. The phrase's identity (here) as a referring phrase depends on its relation to Jane.

(3) Sense-dependence: at least at the moment, and without essaying other thoughts, a speaker attends to Jane only in virtue of grasping, or being capable of grasping, the sense of 'that girl.' The hearer's situation is more complicated. Of course my friend may have been watching Jane attentively without formulating any thoughts she would naturally use the phrase 'that girl' in communicating to me. But if my friend was watching Jane then my friend is in a position to grasp the sense of 'that girl' (or perhaps 'that kid').

(4) Embodied agents: some of the connections among speaker/hearer, significant phrase ('that girl'), and referent (Jane herself) are both causal and cognitively significant (such as the visual connection between the speaker and Jane). Descriptions of either the speaker's meaningful performance, or of the task of understanding facing the hearer, belong at the person-level of explanation. To talk about speaking, hearing, or seeing in the relevant senses is to talk about intelligible activities of persons.

The relations I've labeled referent-dependence and sense-dependence fall out of the intuitive view of conversational tasks sketched above. Consider referentdependence first. To see at what level the dependence lies, consider a case of what you would count as fully successful demonstrative reference. Depending on your preferred philosophy of language, you will cash out success in different ways. For example, if you typically make a firm distinction between semantic meaning and speaker meaning, you will want to consider a case where you judge them to coincide. In such a case, the status of 'that girl' as a phrase whose (public) sense is a constituent of the speaker's belief, or as a referring phrase the appropriate understanding of which would take a hearer to the speaker's intended referent, or however else you wish to cash this out, depends on Jane.

This looks tautologous. If we define 'successful singular reference' as use of an appropriate referring term or phrase in a context where the referent exists, ${ }^{13}$ and then say that a term or phrase is only really a referring term or phrase when a speaker accomplishes successful reference with it, then it is obviously true that the status of the phrase as referring depends on the existence of the referent. But a theory of reference will incorporate something like this claim if it respects our intuitions about what hearers must do to understand demonstrative expressions. Whether one thinks a theory of meaning strictly construed must pay attention to the tasks of hearers depends on how, and how firmly, one distinguishes semantics from pragmatics. The paradigm notion of complete understanding at issue in ordinary 
conversation tracks many features that some would label merely pragmatic. ${ }^{14}$ In any case, however it is labeled, we've seen there is a key difference, tacitly appreciated by ordinary speakers, between (a) fully understanding what someone said, where that requires understanding what determinate move in the language game she made; and (b) being able to characterize some moves a speaker could have made with the (bare) words you heard her utter. ${ }^{15}$ And Jane is needed for the phrase 'that girl' to be fully understandable in the stronger, relevant sense.

In the absence of a referent—as when a speaker has hallucinated an object—a hearer can certainly give an interpretation of what the speaker is likely up to. The interpretation will preserve the speaker's status as reasonable, as wanting to speak sense rather than nonsense. But without the referent of the speaker's demonstrative phrase, we can't construe the speaker as intentionally doing something determinate (something known to us). We can only hold open the possibility that she is doing something or other.

Now consider sense-dependence. The speaker's only way of thinking of Jane (at that particular moment) is bound up with her ability to pick her out perceptually. So there is no way to specify what the speaker is thinking without referring to Jane, and referring to Jane as the speaker does: non-descriptively. But if an observer is able to report the speaker's thought or speech transparently, she is thereby able to grasp the sense of 'that girl.' Her relation to Jane is similar enough to the speaker's relation to Jane to give her that ability.

This is the analogue for sense-dependence of the trivial truth about referring expressions discussed above. The speaker is now engaged with Jane demonstratively. In order for anyone else, or the speaker herself later on, to engage with Jane in the way the speaker then does, the engagement must constitute, or suffice for, a grasp of 'that girl.' Again the trivial truth points to one less trivial. If the speaker herself-as opposed to a sub-personal part of her-is represented as engaged with Jane, then in that representation, Jane needs to be picked out in a way that respects how the speaker could herself at that time be engaged with Jane. (No such requirement holds if we are instead representing the speaker's retinal nerve as stimulated by light reflected from Jane. ${ }^{16}$ ) We're supposing that the speaker is cognitively engaged with Jane because of her perceptual connection to her, and not because she is deploying a definite description that happens to be satisfied by Jane. In that case, relevant features of the speaker's perceptual relation to Jane need to figure in the hearer's relation to Jane. It is the relation itself that is doing the work, so the hearer needs to relate to Jane in a way that is adequately similar to the way the speaker does. ${ }^{17}$ This generalizes beyond the speaker's actual audience: to represent the speaker as referring to Jane, Jane needs to be picked out (in that representation) as the speaker picks her out. And anyone representing the speaker who manages to do that will either grasp, or be immediately able to grasp, the sense of 'that girl.'

Referent-dependence and sense-dependence are types of tight connection between aspects of a total package: successful communication with demonstratives. That formulations of the connections can sound trivial is due to their being connections 
within what is admitted (for the purposes of discussion) to be a genuine whole. Obviously, if we are talking about wholes, there are tight connections among their parts considered as parts. The point of interest for a potential analogy with wholes united by expressive ties is the way these two relations function to keep reference in the picture as an agent's determinate act. Only if the referent and the sense are available to a hearer can she fully engage with a speaker's communicative act. In their absence-if there is no girl on the playground, or if the hearer can't get in a position to grasp the sense of a demonstrative reference to a girl who is there-then a hearer can only offer interpretations of what kind of engagements might have been possible.

\section{EXPRESSION}

\section{A. A TEMPLATE FOR ACCOUNTS OF EXPRESSIVE WHOLES}

Analogues of the same four connections present in successful communication with demonstratives mark our expression of our states. Before supporting this claim, I'll discuss a general similarity between the two cases. Arguments against granting sui generis status to either demonstrative reference or expression usually involve an attempt to show that the jobs done by them can be done by descriptions. That is, phrases like 'that girl' are reconstrued as abbreviations for definite descriptions. And expressive activities, whether verbal or not, are reconstrued as codes for descriptions of a subject's present state of mind, or of the response she desires from her audience. Anti-descriptivist moves on expression's behalf sometimes court reductive behaviorism, or undermine descriptivism only about qualitative states and not anything else to which our attention might be directed. A similar problem affects many discussions of singular reference: it is hard to keep hold of the possibility that a subject could be thinking about something, that it could be cognitively significant to her, without her thinking about it by describing it. ${ }^{18}$ That sense could be non-descriptive is a missing option, both for reference to middle size dry goods and expressible states of subjects.

For example, consider the implied dilemma in Joachim Schulte's rejection of the claim that avowals are primarily used to make claims about our mental states: "In speaking of my being afraid I do not normally mean to describe it; I mean to be consoled, for instance" $(1993,161)$. Schulte assumes that because the appropriate response to an avowal of fear would be to offer consolation, and because most people avowing fear within earshot of others would know that, it can't be that the avowal is about the fear. But this is because his model for an avowal of fear being about that fear is that the avowing agent is undertaking to describe her fear, presumably with the sole purpose of informing an audience about it.

The blind-spot in this particular way of dealing with a descriptivist threat to expression's status is thrown into relief by comparison with the referential case. Schulte's dilemma is transparently odd in the case of demonstrative reference. Suppose, while building a deck with you, I shout, "That bolt is loose!" I certainly 
"mean" (in Schulte's sense) for you to do something right now to secure it. But I'm certainly thinking about it, and communicating a claim about it to you. And I expect you to be able to think about it non-descriptively because I expect it will be immediately perceptually salient to you in the way it is to me. I expect you to secure the bolt because I expect you to grasp the sense of what I said. You're in a position to do the securing because you're in a position to do the grasping. A speaker who successfully communicates with a demonstrative is not related to the referent of that demonstrative merely behavioristically. But neither is being in that relation (or, for the hearer, coming to be in it) a matter of deploying a description. Accounts of expressive relations as sui generis also need to construe subjects as cognitively but not descriptively related to their expressed states.

In both cases, the status of one aspect of the total phenomenon - of reference, or expression-as person-level essentially depends on its connection to another aspect of the total phenomenon. I will argue for this in the course of arguing for the presence, in expressive wholes, of analogues to the four connections presented above. So consider, first, a case of natural expression - of my weeping and my sorrow. (I'll discuss non-natural expressions below.) Here are four candidate relations between them:

(1) Expression: my weeping expresses my sorrow.

(2) Expressed-dependence: my weeping depends on my sorrow in the sense that my sorrow must be referred to in any description of my weeping that keeps it a person-level phenomenon (as opposed to a sub-personal phenomenon). Eyes can weep in the way wounds do; but then none of the eyes, the tears, or the weeping is expressive.

(3) Expressing-dependence: my sorrow depends on my weeping in the sense that picking out my sorrow as a possible state of a person requires a specification of it that adverts to (actual or possible/appropriate) weeping. This is sense-level, rather than reference-level, dependence..$^{19}$ It is not the claim that sorrow itself is a disposition to weep, but the claim that the specification of sorrow as sorrow involves (among much else) the concept of weeping. ${ }^{20}$ The relevant involvement may be cashed out in different ways. In some cases, the specification of a human mental or emotional state is descriptively complex, and includes concepts of behavior expressive of that state. In other cases the dependence will be less robust. It may, for example, simply be that no one would be competent to apply the concept of the state who wasn't also competent to apply the concept of the expressive behavior.

(4) Embodied agents: some connections among subject, emotion or mental state, and overt behavior are both causal and cognitively significant.

Before arguing that these connections obtain, I will ward off a potential misinterpretation of my aim. I have suggested that looking at demonstratives would help make plausible the idea of tight but not mysterious connections among expressive 
phenomena. Some readers might consider Wittgenstein's notion of criterial relations to be an approach that makes expression interesting only by shifting the burden of mystery (to criteria). And the above presentation of the four connections sounds quite like Cavell's development of Wittgenstein's views. ${ }^{21}$ Those not antecedently sympathetic to Cavell's position may argue that not much light is shed by Cavell's observation that criteria are criteria for something's being so rather than for its being so. They will worry, then, that my candidate connections among elements in natural expressions look like old-fashioned conceptual connections between expressings and what they express. (For example, for something to be sorrow just is (in part) for weeping to be an appropriate expression of it. And for something to be weeping just is (in part) for it to be (rationally, not brutely) caused by sorrow.) And (the objection continues) these connections are either theoretically tractable, in which case they lead to reductive behaviorism; or they are not, in which case they are useless.

My proposal is indeed that there are conceptual connections among the elements in expressive packages. What is distinctive about my proposal is its claim about what the conceptual connection guarantees. I am not arguing that the connections guarantee first- or third-person access to inner states. I am arguing that they guarantee that the phenomenon in question is a person-level one. I've claimed that the same connective structure, and the same pay-off, is at work in the case of demonstrative reference. Finally, this analogy helps someone who wants to see expressive connections as conceptual connections fend off the charge that she is aiming at an irrealist treatment of expressible mental states. The claim that there are tight connections between demonstrative phrase and referent isn't usually in the service of any kind of irrealism about either.

\section{B. ARGUMENTS FOR EXPRESSED- AND EXPRESSING-DEPENDENCE}

Again, it is the second and third connections that require most explication. But here a preliminary clarification of the fourth connection is also needed. If a weeping person is sorrowing, her sorrow is the cause of her weeping, if only in the counterfactual sense that had she not been sorrowing, she would not have wept. ${ }^{22}$ But this causal connection is not brutely causal. ${ }^{23}$ That is, weeping when sorrowing is appropriate, not just predictable. Sometimes the appropriateness can be cashed out like this: her sorrow is the weeping person's reason for weeping, where her weeping is voluntary in the sense that she can affect the manner of her weeping, and how rapidly it is brought under control. ${ }^{24}$ Likewise with a kiss, though that is voluntary in an even stronger sense. For behaviors whose voluntary status is more tenuous, as crying is for at least some of us at times, the notion of appropriateness can still apply. Many such behaviors feel satisfying to the subjects in the states they express. So we might think of them as worth doing, even if we don't feel ourselves to have a choice. (Think of efforts to reassure young boys that it is acceptable to cry, because crying makes you feel better.) I take it that someone who found nothing 
plausible in either claim (1) or claim (4) is unlikely to want a positive account of expression. ${ }^{25}$ So I will focus on what support can be offered for connections (2) and (3). (The details of this support will also help flesh out the notion of appropriateness appealed to in unpacking claim (4). ${ }^{26}$ )

Consider expressed-dependence first. It claims that an expressing depends on what it expresses for its status as a person-level phenomenon. In defending this claim, I will use Bar-On as a foil. Bar-On makes room for a weak version of expressed-dependence. She does so despite rejecting any conceptual connections between expressed states and expressings that would either conceptually guarantee the truth of avowals like "I'm so sad," or court reductive behaviorism (Bar-On 2004, 325). A comparison between claim (2) and Bar-On's weaker connection will show that a fully satisfying account of expression requires something stronger than Bar-On takes herself to provide. It will also show such a stronger connection need not be grounded either in behaviorist irrealism about expressed states or in flatly constitutive approaches to first-person authority for expressions. ${ }^{27}$

The general motivation for Bar-On's rejection of tight conceptual connections between expressions and expressed states is that she wants particular sentences or gestures to count as expressive products of a certain kind, even when they are put forward by insincere agents, or actors in a play. But Bar-On acknowledges that even with a firm distinction in place between acts (expressing one's anger) and the products of acts ("You idiot!"), this move will seem troubling. That's because she treats 'express' as a success verb.

The problem arises because Bar-On not only wants false avowals-e.g., an utterance of "I' $m$ so sorry" by someone who feels no regret - to count as expressive products. She wants agents' production of them to count as expressive acts (2004, $325-328$ ). But there is a tension between counting an insincere utterance of "I' $m$ so sorry" as an expressive act while construing 'express' as a success verb. Bar-On resolves it by finessing her commitment to disjunctivism in the philosophy of mind. She doesn't emphasize that her position essentially depends on a tacit commitment to a conceptual connection between expressions and expressed states.

Disjunctivism is a cluster of views about perception, belief, and justification. It holds that if "a subject's state can provide her with epistemic warrant for certain beliefs," then when such candidate beliefs are false, the subject who holds them is not in the state that would have warranted them (though she may take herself to be) $(2004,391) .^{28}$ For example, suppose a perception of a rat on a desk suffices as warrant for the belief that there is a rat on that desk. If a subject believes falsely that there is a rat on her desk, then she was only under the impression that she was seeing a rat. There was no perception of a rat on a desk at all-only an apparent perception. Bar-On accepts disjunctivism about the states that warrant avowals. That is, she takes it that when avowing, and only then, "one's epistemic warrant [is] the same as the rational cause of one's behavior" (2004, 391; original in italics). A false belief that one is in pain is different from a true belief to this effect not only in its truth-value but in the agent's entitlement to it. She is not in 
the same mental state, though it may appear to her exactly like a case of her being in pain (392-393).

Now, Bar-On wants to accept this type of disjunctivism while counting as expressive even acts whose products do not truly ascribe states to their agents. So she needs some minimal way to unite both "acts of avowing truly and acts of avowing falsely" $(2004,395)$ as actions of a single kind it will be appropriate to call expressive. Her solution is to appeal to an interpreter's perspective on the relevant acts. Bar-On explains that what unites acts of these two kinds is that "both are acts of speaking one's mind whose characterization as reasonable acts may require mentioning the (possibly absent) self-ascribed states of mind." 29

According to the philosophy of action Bar-On accepts, it is not brute but rational causation that figures in the explanation of actions. We must be able to characterize an act as reasonable, at least in the sense of rationally intelligible, in order to characterize it as an act. ${ }^{30}$ This suggests that the uttering of a sentence is an act - and hence is appropriately interpreted by an audience as something a person did - only if the act is characterized in terms of its relation to an (appropriate) inner state. If so, the point covers all expressive acts. It isn't just a tool for maintaining the expressive status of the performances of confused, insincere, or Equity-cardholding agents. An interpreter's appeal to an appropriate mental state is necessary to the characterization of all expressive acts as expressive acts.

A point drawn from the referential case will help to show why the point should be this general. Recall that on the playground, my friend, to understand me (by fully understanding what I said) needed to perceive Jane. And even to interpret me as at least trying to say something significant, she needs to describe me as attempting to communicate about a perceptible girl. Now, the audience to an expressive act perceives it as an act (a person-level production) only if they can advert to what it expresses. In cases where a successful expressing is fully appreciated by its audience, the audience can do this because they learn of (for example) sorrow by seeing weeping, or by hearing an avowal of sorrow. In cases where someone is dissimulating, or where there is some kind of expressive failure, the audience can formulate the defeasible claim that the person is weeping (rather than e.g., that her tear-ducts are watering) only by reference to a state appropriately expressed with weeping, such as sorrow. This is akin to that interpretation that falls short of full understanding in the referential case. That is, it is a rationalizing strategy. Sorrow may be functioning only as a place-holder for some other state of a kind whose presence would keep the weeping at the person-level. In the fully successful case, the state to which we refer, in properly characterizing the relevant act, is also the rational cause of the act. But in every case, a behavior's status as action depends on the possibility of adverting to an expressible state. To keep an expressing at the person-level, as something appropriately described and explained in terms of its intelligibility, requires appeal to what the expressing expresses. But that just is what (2), expressed-dependence, asserts. ${ }^{31}$

Now consider expressing-dependence. It constrains how we may comply with expressed-dependence, as sense-dependence constrains how we may comply with 
referent-dependence. In the referential case, the referent must be characterized in a manner that reflects the nature of the subject's cognitive relation to it. Here, the expressed must be characterized in a way that respects the subject's perspective on that state.

Note, first, that our expressive activity is often spontaneous, not epistemically mediated, and yet almost never surprises us. Second, and perhaps more controversially, we take successful expressive activity to get interpreters close to an expressing subject's state, and her first-person perspective on that state. It gets them closer than either the issuing of (mere) reports or the performance of other non-expressive activity could do. The question of how expressive activity does this presumably waits on a particular positive account of expression. But the possibility of this closeness should be preserved by any positive account. Otherwise, expression wouldn't turn out to be distinctive enough, compared to other methods of learning about our fellows, for us to give it the weight we do in our personal lives, or for us to hope an account of it will carry philosophical burdens. We could make room for this possibility of closeness if expressive activity were necessary to a proper characterization of what it expresses. We could also appeal to that necessity to explain our typical lack of surprise at our own (typically unplanned) expressive behavior.

Take an example of a non-natural, linguistic expression-such as an utterance of "What a travesty!" in sorrowful disgust. Consider how expressed- and expressing-dependence look in this case. In any ordinary situation, it will be clear that the emergence of the phoneme-string corresponding to an utterance of "What a travesty!" was an intentional act. Nevertheless, an appeal to an expressed state is needed to characterize the utterance as an agent's act in the following sense. Only by making such an appeal do we make the kind of interpretive move that could count, in the central cases, as understanding someone by fully understanding what she said. Only if the adverted-to state is present is the audience understanding the subject, engaging her on her own terms, by fully appreciating what she said. But only if some such state is adverted to will the audience be able to form hypotheses about what the subject might be up to, so that she can be seen as at least intending to be fully engageable.

Expressing-dependence looks easier to accept in the case of linguistic expressions. Some philosophers, after all, have argued that to entertain beliefs-at least at any serious level of complexity - one must have the capacity to express those beliefs linguistically. ${ }^{32}$ And if an utterance could express a mental condition, the mental condition in question must have some tight ties to the content of the utterance. Bar-On allows ties of this kind in the case of avowals and argues that they explain the presumption in favor of avowals' truth (2004, 413-414). Someone who is bored, provided she speaks English, just is thereby in a position to (as Bar-On puts it) speak her mind, to express her being bored, by avowing, "I'm bored." And here the expressing-dependence is clear because the expressive product contains the very concepts used to pick out the expressed condition. ${ }^{33}$ 
But expressing-dependence is also present when subjects' expressive activity is non-linguistic. In order for subjects to be rarely surprised by that activity, there has to be a distinctive connection between the activity and the state. Such a connection is also required if interpreters are to be correct in taking expressive activity as more than a mere indication that the subject is in the relevant state. Since natural expressive activity isn't semantically contentful, it won't connect to what it expresses by naming it. But a feature of that connection carries over to this case. The expressing activity serves as a guide to the expressing subject's take on the state she's in. An interpreter who follows this guide will be able to respect that take when he attributes a mental state to her. This preserves the possibility that in his third-person approach, he is appreciating what it is like for the subject herself to be in the relevant state. Interpreters need to classify an expressed state so as to reflect the fact that a subject in that state is poised to express it as she does. Interpreters fulfill this requirement in different ways, however, depending on whether or not a subject's expressing is linguistic.

The analogy with the use of demonstratives is exact. There, being able to represent a subject as making a determinate utterance required us to grasp how she was in fact connected to the referent of her demonstrative utterance. Here, being able to construe a subject as in a determinate state requires us to have a grip on how she actually is in the state she's in. And 'how she is' is expressing, or poised to express, her state in this way (e.g., by weeping). So the full interpretation of the subject as in a definite state, rather than as in some-plausible-state-or-other, requires that one keep the expressing in the package as part of how one specifies the expressed.

Even when a state like sorrow has a relatively narrow range of canonical expressions, it is possible for a behavior not in that set to count as an expression of the state. And it is possible to be surprised by the way another person, or, in special cases, one's own self, expresses a state like sorrow. Acknowledging expressing-dependence doesn't require us to ignore these complexities. But it means that when one realizes that some unusual behavior really is expressive of sorrow, one learns something about sorrow, and not only something about the sorrowing person before one.

For expressive activity to count as person-level, and for it to make possible full engagement with expressing subjects, we need to respect expressed- and expressingdependence in our approach to expressive wholes. It remains to be seen whether a slide into behaviorism is a necessary consequence of this approach. I will again use Bar-On as a foil, in arguing that it is not. The argument will also generate additional support for expressing-dependence.

\section{TIGHT CONNECTIONS DO DOT ENTAIL BEHAVIORISM}

Bar-On is most clear that the connections her account makes between mental states and expressive behavior are minimal when she is defending herself against the charge that her account makes those connections too tight (2004, 421-424). Bar-On asserts that while she thinks expressive relations are distinctive, and "expressive behavior is sufficient to show the state it expresses" (421), expressive behavior is 
neither necessary to nor sufficient for a subject's being in an expressible state. ${ }^{34}$ She puts the point very strongly:

The only commitment regarding a connection between mentality and behavior that [my] account incurs is through the claim that mental states, unlike non-mental bodily states and psychological dispositions and traits, can be and often are shown (and made perceptible) through subjects' behavior. (422; first emphasis added)

Bar-On acknowledges that "if the expressive behavior you're witnessing can suffice to let you see my being in $\mathrm{M}$ [where $\mathrm{M}$ is some mental state], the behavior must in some sense be part of my being in M" (422). But this kind of part-whole relation is not a constitutive one, Bar-On insists. Specifically, "this does not mean that for any given $\mathrm{M}$ there will be characteristic expressive behavior that is essential to being in M" (ibid.). ${ }^{35}$ Bar-On's account of self-knowledge attempts to make do with only a negative characterization of expression. But her appeal to 'characteristic' here comes from her sympathetic exploration of a positive account of expression in terms of showing that draws on Mitchell Green's work. Green suggests that expressive behavior can make what it expresses perceptible if the behavior is a characteristic component of the expressed state $(2007,86-87){ }^{36}$ This approach is in the background when Bar-On contrasts the characteristic and the constitutive. As she explains, "I can see the tree in my yard by seeing one of its familiar branches, which is clearly part of the tree. Still, the branch is not an essential part of the tree" (ibid.).

The analogy is revealing because of a difference between the tree case and expressive wholes as Bar-On officially construes them. True, no single branch is essential to the tree-not to its existence, not to its being a tree, and not to its being the particular tree that it is. (And a branch can still be a branch, when it lies severed on the ground.) But if a perception of a single branch does suffice for a perception of a tree, that tree must have an organic unity in which that branch participates. Characteristic components can't enable perception unless some real unity, appropriate to the kind of object or state in question, connects them to that of which they are components. What is needed in the case of human expressive behavior is something to play the role of the organic unity of the tree-something that unites weeping and sorrow so that one can see sorrow by seeing weeping, even though that very person could have been in sorrow and not wept. Without it, there is no warrant for taking the perception of weeping to be, in the right sort of case, the perception of a person's feeling sorrow.

Bar-On doesn't put forward an account of a relevant personal unity. But expressive activities won't count as characteristic components of expressed states unless there is, for each of us, a serious unity of our minds and our bodies, our feelings and our gestures, our passions and beliefs and words. The unity must include both instinctual and acquired reactions, and both non-verbal and linguistic expressings. Only then would it be possible to see someone's being afraid by seeing her shrinking posture, or hear someone's being furious by hearing her say, "You are 
lower than low!" That kind of unity is presumably itself acquired and developed, at least in part. We aren't, at birth, able to have states that "What blasphemy!" appropriately expresses.

We are eventually able to be in such states, and arguably do eventually display a unity of mind and acts, including speech-acts. A plausibly non-mysterious form of that unity will depend heavily on the unifying force a person's perspective on her self and her world brings to her states and her actions. But any position appealing to that unity will end up entailing some version of expressed-dependence and expressing-dependence. That's because caring about a subject's perspective in the relevant way just is to take the paradigm form of understanding a person to be: interpreting her as engaged in determinate activity, not just in some-reasonableactivity-or-other. That form of understanding requires us to foreground the perspective of those whom we interpret in a way that entails expressed-dependence and expressing-dependence.

So if Bar-On were to develop fully her suggestive line on expression as sufficient to enable the perception of what it expresses, she would end up with a positive account of expression that fit the template outlined here. Of course, she could decline to accept the kind of tight connections between elements in expressive wholes that the template lays out. But then she would run the risk of losing real distinctiveness for expressive connections. In any case, the tight connections laid out in the template do not entail a behaviorism of the kind Bar-On was concerned to avoid. When characterizing a behavior as a person's determinate action, we need to refer to an expressed mental state. But that doesn't make that action a guarantee of the presence of that state. And when we characterize a subject's expressible state, we need to respect her point of view on it, and so we need to acknowledge that she is disposed to express that state as she does. But that doesn't reduce the state to the disposition to produce such an expressing.

However, because Bar-On believes she can account for the distinctive status of avowals with only a negative account of expression, she herself does not present a fully fleshed-out account of expression as showing. In her provisional presentation of such an account, she explores the possibility that all expressive showing is perception-enabling. Mitchell Green, who does put forward a complete positive account of expression as showing, explicitly denies this. For Green, some expressings show what they express without enabling its perception. ${ }^{37}$ But like Bar-On, Green faces the problem of delineating exactly which showings are expressive, since not all are. He limits what can be expressed by stipulating that only introspectible states of subjects can be expressively shown $(2007,39) \cdot{ }^{38}$ I will endorse a version of this position. He also limits expressive behaviors to those that show an introspectible state and are designed to show it. Expressive behaviors, according to Green, have to be signals: features that not only convey information but were designed for their ability to convey that information. ${ }^{39} \mathrm{I}$ will argue that this limitation wrongly rules out, as not expressive, some behaviors that enable perception of emotional states. Green has a number of reasons for his design requirement. The connection it allows 
him to make between expression and communication is especially significant, but the connection can be secured in another way. The resultant account of expressive showing would fit the template laid out above.

\section{GREEN'S POSITIVE ACCOUNT OF EXPRESSION AS SHOWING}

Many expressions of emotions, on Green's view, enable the perception of those emotions. ${ }^{40}$ Green holds that certain emotional states have, as characteristic components, distinctive facial signatures, physiological responses, and dispositions to (specific) behaviors $(2007,88,91-92,134)$. For example, "being angry at someone just is, inter alia, to want to hit or otherwise harm them" (127). So if I slap Smith, my slap shows my disposition to injure him, and hence makes my anger perceptible. ${ }^{41}$ If a behavioral disposition or an urge is a characteristic component of an emotion, then a manifestation of the disposition, or an action that satisfies the urge, will show that characteristic component. That will enable the perception of the relevant emotion. Green notes that one can show one's emotion without aiming to do so. When angry at Smith, I may slap him just to satisfy the urge to injure. Likewise, I might show affection by embracing someone without aiming to show my affection, to her or anyone. I might simply feel like embracing her. ${ }^{42}$

Bar-On could count the slap and the hug as expressive, on her version of the characteristic component model, simply because they do show anger and affection (respectively). Green, however, counts them as expressive only because they also satisfy his design requirement. Slapping Smith, or even gouging out the eyes in a picture of him, do enable perception of anger. They are, respectively, actual or in-imagination satisfactions of urges that are characteristic components of anger. They count as expressive because, in addition to showing anger, they are designed to show anger. The actions aren't designed by the slapper or the gouger to do this. Green asserts, however, that injuring $X$, making as if to injure $X$, or attacking something strongly affiliated with $\mathrm{X}$, are all signals of anger at $\mathrm{X} .{ }^{43}$ Whether the design is biological, cultural, or a mixture of both need not be settled $(2007,37)$. What matters is simply the fact of design. Green doesn't explicitly discuss the designed status of embraces. But they also look like plausible candidates for signal status. I can employ whatever style of embrace is common in my culture simply to satisfy an urge to be close to someone I love, and hence without any intention on my part to show my affection. But that action nevertheless seems to have been designed (biologically and/or culturally) to show affection (to its recipient and/or to observers).

It may be that many characteristic components likewise turn out to be signals. (Facial expressions are a clear case of this that Green discusses.) But Green is committed to withdrawing the status "expressive" from any behavior, even a behavior that is a characteristic component of an expressible state, that turns out not to be designed to show the relevant state (2007, 27 and 142-143). And whether some behavior is designed, biologically or culturally, is an empirical question. Common 
sense could be wrong about what it counts as expressive, because it could be wrong about the designed status of various behaviors (27). ${ }^{44}$

There are some behaviors that look as if they would count as expressive on Bar-On's characteristic component account, but which are likely to fail the design test. Consider, for example, snuffling in the hair of a loved one, perhaps while she sits on your lap (if she is a child), or while you lie next to her (if she is a romantic partner). This can be done without any intention to communicate affection. For example, I sometimes curl over my sleeping daughter to do this, and there is no one else with me as I check on her in her bedroom. I do it simply because I like breathing her scent, and feeling the warmth of her scalp. The action immediately satisfies a desire for a certain kind of closeness, which desire is a characteristic component of affection (or, perhaps, affection of a certain kind-parental or romantic). A suitably placed observer could perceive my affection for my daughter by perceiving my burying my face in her hair, or by perceiving the way I do this. Green can't grant my behavior expressive status, however, except by making a tentative judgment that it is designed (though not by me) to show affection. This judgment looks less plausible than it did in the case of embraces. Yet when I have seen other family members do this to my daughter, I intuitively treat it as expressive of their affection, just as I treat their embraces of her on other occasions.

Faced with such cases, Green has three options. He could say our intuitions were wrong: not all the behavior we pre-theoretically class as expressive turns out to be expressive. Or he could find a plausible design story for some such cases. Finally, he could argue that any action that immediately satisfies an urge that is a characteristic component of an expressible state is in fact designed to show that state. So all kinds of slaps and all kinds of caresses turn out to signal anger and affection, respectively. (And so on for every relevant triad of action, urge, and state.) But while this last option might not over-broaden the category of expression, it surely risks watering down the concept of design. ${ }^{45}$ Presumably, then, Green would stick to the claim that a specific behavior counts as expressive only if it was itself specifically designed to show what it does. Thus, even when we have a behavior that is showing an emotion, and is even sufficient to show because it is a characteristic component of what it shows, its status as expressive is not secure until it has been proven to be a signal. In taking this route, Green might try to mitigate the number of cases where a loss of expressive status looms. He could suggest that many of these showing behaviors come bundled with other behaviors (such as facial expressions) that are signals. So while snuffling in a child's hair won't express love for her, the repertoire of behaviors in which it is usually embedded will include clearly expressive ones. So the typical hair-snuffling parent will be expressing love while hair-snuffling, but not by hair-snuffling.

To keep the snuffling expressive, we need not dispute whether it is a signal. We could dispute Green's contention that common sense links expressivity and design. Green makes this link fully explicit as follows: "To the extent that we take an item (behavior, artifact, etc.) as expressive, rather than just as indicative, of a state of 
affairs, to that extent we also take it as having been designed (consciously or not) for the purpose of showing that state of affairs" $(2008,393) .{ }^{46}$ On this analysis of the notion of expressivity, we are all committed to withdrawing the label "expressive' from behavior that turns out not be designed to show what it does, whenever our views about designed status turned out to be incorrect. Green is right that we can't settle what is designed simply by consulting folk-biological intuitions about what behaviors are expressive. He goes wrong in taking there to be a link between folk intuitions about expressivity and folk intuitions about design. Such largely conceptual disputes are notoriously difficult to adjudicate. I won't argue directly that our ordinary notion of expression - the one that plays a significant role in our lives together-lacks any conceptual connection to design-status. Instead, I will show that two benefits of imposing the design requirement can be secured in other ways. The category of specifically expressive showings can be delineated without it. And the communicative success of expressive exchanges can be respected in its absence.

Before considering these two claims in turn, a clarification is in order. Green locates human expressivity in the context of an evolutionary account of expressive behaviors, including facial expressions, that are (Green argues) also deployed by non-human primates to expressive effect. But severing the conceptual link between being expressive and being designed has no implication for how many expressive behaviors are in fact designed to show what they express. It would not pre-judge questions about how our capacity to communicate evolved. It is also compatible with the possibility that we only managed to develop conventional signals because we were endowed with a rich repertoire of natural ones. We can deny that expressings must be designed to show what they express without challenging empirically grounded approaches to the origins and structure of communication.

Now consider the first claim: that the design requirement is not needed to identify expressive showings. Recall that Green (properly) counts as expressive some behaviors that are not intended by behaving subjects to show what they do. ${ }^{47}$ But rejecting an intention requirement-as Bar-On also does-means one cannot appeal to the absence of such intentions to explain why we intuitively deny expressive status to certain behaviors, like blushes and galvanic skin responses, that may very well show a subject's mental state. ${ }^{48}$ Such behaviors cause Green particular trouble. On his "affect program" approach to emotions, undergoing various autonomic nervous system changes is part of what it is to be in a particular emotional state. If such changes are perceptible — as blushing clearly is - then they look like good candidates for characteristic components of the relevant emotion. Suppose Green had allowed characteristic-component-based perception-enabling showing (of introspectable states) to suffice for expressivity. Green would then, counter-intuitively, have to count these emotion-components as expressive behaviors. Because of his additional design requirement, he is able to rule these changes out as non-expressive, because neither appears to have been designed to show the emotions it partially comprises. (Given his own commitments, he'd have to rule either behavior back in if it turned out to have been so designed. ${ }^{49}$ ) 
Here is an alternative way to rule out galvanic skin responses, and possibly blushing. Consider whether or not the candidate expressive behavior is accessible to the subject first-personally. Perhaps this access is via proprioception. Or perhaps the behavior is a voluntary action and hence something the subject can be aware of in the non-observational way we are aware of our actions..$^{50}$ If not, it isn't expressive. That rules out galvanic skin responses, and leaves blushing where, perhaps, it ought to be. Blushing is a behavior we aren't sure how to classify, in part because people subject to blushing differ in the extent to which they describe it as something they can modulate, or as a sensation they can distinguish from the sensation of having a flushed face after exercise. Importantly, the first-person accessibility requirement is a counterfactual requirement. That is, we can express an emotion by an expressive activity of which we are not aware at the time of expression. Depending on how one's attention is directed, one can sometimes, in the grip of a profound emotion, fail to realize initially that one $i s$ weeping, or screaming. ${ }^{51}$ But both are behaviors that one can know of in a first-personal way. My alternative to Green's design requirement is as follows: to the extent that we take some behavior as expressive, to that extent we take it to be a behavior of which a subject can be first-personally aware.

Note that in the explicit statement quoted above, distinguishing expressivity from mere indication, Green is talking about expression in the most general sense. For him, this includes not only perception-enabling showing, but also certain showingsthat and showings-how. And it includes not only self-expression-the expression of introspectible states by subjects in those states-but expression in even the aesthetic sense (as when a heavy-looking statue expresses dejection).$^{52}$ Obviously, the features that are candidates for expressive status in art works are not knowable first-personally, because they are not features of subjects. Suppose Green is right that there is a uniform notion of expression in play across aesthetic and self-expressive contexts. Even so, design need not be an independent requirement on expressive items. Note that if expressive showing is not of the perception-enabling kind, successful showing appears to require design. Any artifact that shows an emotional state will have been designed to show something. (Artworks can express states their creators didn't design them to express. But the work would not exist, and hence would not express all that it does, unless the artist had designed it to show some of what it does.) The connection is even tighter with any human behavior that shows without enabling perception of what it expresses - as with utterances, on Green's account of them. If my utterance could suffice to show you that (for example) I intend to pick you up at the airport, it must have been designed to do so. ${ }^{53}$ Many means of expression are able to express what they do only because they are in fact signals. ${ }^{54}$ But this can be acknowledged without requiring all expressive means to be signals. We could lift the design requirement and sort perception-enabling showings by means of the first-person accessibility requirement. This would be compatible with acknowledging that in many contexts, a behavior or feature will manage to show, and hence express, only because it is designed to do so. 
Consider, now, the second benefit of the design requirement: it serves to keep expression in focus as a communicative phenomenon. It is significant that much of our expressive behavior is actually taken by others to express what it does. While one can express when all alone, observers-when there are some-usually and readily appreciate what one expresses. This is one of the reasons why we value expressivity: it helps us feel in touch with each other. A positive account of expression ought to respect this, if not explain it. One method for doing this is closed to Green, because he denies that expressive activity need be intended by its agent to be expressive. He can't, therefore, try to explain the typical success of expressive behavior by suggesting that expressing agents design it to be understood as expressive by their audiences. But if expressive behavior could be designed for audience appreciation by something other than the expressing subject, we'd have a link between expressive activities and their usual audiences. Something that is designed to show is going to be designed to show to some possible audience. (Of course, an instance of showing may occur even if no actual member of that audience appreciates the showing.) But requiring expressings to be designed is not the only way to respect the communicative success of much of our expressive behavior.

Suppose the typical consumers of expressive behavior are designed, perhaps sometimes in the sense of trained, to perceive expressive behavior as expressing what it does. This would go a great distance toward explaining the extent of our communicative success. Consider again actions that are characteristic components of particular emotions, or are manifestations or satisfactions of dispositions that are characteristic components of those emotions. It is not in dispute that someone can engage in those actions, and thus show her emotions, even if her only reason for doing so is the satisfaction this brings to someone in the relevant emotional state. Take, for example, actions that have a good claim to being natural, rather than conventional, characteristic components of fear: crouching, throwing up one's arms to cover one's face, or holding one's own torso while cringing away from the object of the fear. We perceive those as fearful postures. ${ }^{55}$ It is useful to us as a species that fear can be communicated in this way. We often face common threats, and the more rapidly more of us can take action to avoid them, the better. It is also sometimes useful for the object of our fear to be shown our fear. Suppose, that is, the object of our fear is a human threatening to strike us, rather than some falling rocks. In such a case, it is useful for that human to realize we pose no kind of threat and can safely be left alone; or, in more socially loaded contexts, that we already "know our place" and don't need to be forcibly reminded of it. But these practical benefits can be secured without the fearful postures themselves being designed to show fear. The benefits could be secured if we are designed to see them as fearful.

Any design here is presumably biological. ${ }^{56}$ But socialization might encourage us, more or less explicitly, to perceive a wide variety of behaviors as expressive. Perhaps reminders about which dispositions and states go together help develop our capacity to appreciate certain perception-enabling showings. We are under social pressure to be attentive, and perhaps in responding to this pressure, we get 
better at seeing certain behaviors as characteristic components of expressed states (or as manifestations of those components.) Defending any particular claim about consumer-side design would, obviously, be an empirical affair. ${ }^{57}$ My general point is only that we can lift the design requirement for expressive behaviors without denying that it is often useful for our emotions to be shown, and without denying that they are often shown successfully to our fellows. Expression is in general apt for audience appreciation. But even when that aptness is the result of design, what has been designed may be the typical consumer of an expressive behavior, rather than the produced behavior itself.

\section{E. EXPRESSING-DEPENDENCE AND EXPRESSED-DEPENDENCE, REVISITED}

Rejecting a conceptual link between expressivity and designedness drastically alters Green's account of expression. ${ }^{58}$ But it lets us extend Green's account of perceptionenabling expressive showing to behaviors commonly treated as expressive, such as certain kinds of caresses and crouches. In the preceding section, I showed that even with this alteration, we could rule out non-expressive showings by introducing a first-person accessibility requirement for expressive behaviors. And I showed that audience design is an alternative explanation of the fact that we properly appreciate much of our fellows' expressive behavior. In this section, I show that the resultant positive account of expression fits the template developed in this paper.

This account will trace rational and causal links among the elements in expressive wholes. First, the introspectibility requirement ensures that expressed states are not without cognitive significance to subjects. Second, much expressive behavior is voluntary, even if it is not undertaken with an intention to express. Such behavior-ranging from speech-acts to dance performances-will clearly be personlevel behavior. Where the behavior looks less voluntary, it will still be cognitively significant to the agent if it satisfies the first-person accessibility requirement. If someone is so enraged that she could not have prevented herself from slapping the target of her rage, she is still first-personally aware of her slapping. And the satisfaction the slap gives is her satisfaction: the relation between the urge to injure and the satisfying action is person-level. Likewise for weeping in sorrow or screaming in pain: while these may be involuntary, they are first-personally accessible. Sometimes the person in pain has an urge to weep or scream, and again, the sense of the fulfillment of that urge is person-level and immediate. The less any of these person-level connections hold of some behavior, the less it will count as expressive. ${ }^{59}$ Green's account of self-expression already put such connections in place for much expressive behavior. Adding the first-person accessibility requirement for expressive behavior highlights the presence of these connections in natural expressions, and rules out as non-expressive any behavior that lacks them.

The modified account also includes a version of expressed-dependence. First, an account of expression that depends on the notion of a characteristic component requires a unity between those components and the states they express (by showing). 
The earlier discussion of Bar-On showed that securing such unity also secures some version of expressed-dependence. ${ }^{60}$ Unlike Bar-On, however, Green explicitly denies that all expression is of the perception-enabling variety. However, a version of expressed-dependence is also embedded in his account of the self-expression that is based on showing-that. On his account, subjects express their beliefs and desires by exploiting conventions to show that they have those beliefs and desires. The conventions are associated with norms making subjects liable to loss of credibility if they turn out not to have the beliefs and desires in question. (Since losing credibility, and hence the ability to participate in important conversational spaces, is a serious threat, faking compliance with the norms carries real risk.) But those norms make sense-level connections between the relevant states and the acts that express them. ${ }^{61}$ The connections amount to expressed-dependence because interpreters must refer to the expressed state when interpreting the sounds coming from a speaker's mouth as a person-level performance. Otherwise making those sounds can't be interpreted as an act of making oneself liable to certain penalties, and hence as an act of determinate self-expression.

The modified version of Green's account also includes expressing-dependence. Recall that expressing-dependence is a way of respecting expressed-dependence properly. We can only interpret an expressing subject as doing something determinate if we pick out the state she's expressing in a way that is sensitive to her take on that state, her way of being in it. By stipulating that expressible states be introspectible, Green has already made a significant move in this direction. He acknowledges that a state that can be known by introspection may, perhaps, be knowable in other ways (such as a third-personal, neuro-physiological way) ${ }^{62}$ The requirement is only that an expressible state must have at least one introspective way of being known. If one is characterizing a state as part of an expressive whole, then specifications of that state will need to fit the way the state is known in introspection. (Or: they will need to fit the way the state could be known in introspection (if the subject has yet to shift her attention to it).) Linking the specification of what is expressed to the subject's (also first-personally knowable) expressive activity is a simple way to do that. It ensures that expressed states are specified so as to make clear that they can meet the introspectibility requirement.

The discussion above noted that expressing-dependence looks easier to secure in the case of linguistic expressions, both generally and for Bar-On's account in particular. And this is true for the modified version of Green's account as well. When a subject does express her state linguistically (whether via an explicit selfascription or not), using the content of her utterance to guide our specification of the state she expresses ensures that expressed-dependence is respected in the right way. It ensures that the expressed is specified as cognitively significant to the subject.

But expressing-dependence, and its determination of how to satisfy expresseddependence, extends more broadly once Green's account is modified. With the first-person accessibility requirement in place, picking out behavior as expressive requires tracking the subject's own mode of awareness of it. Classifying behavior as 
smiling, rather than as (say) the tightening of certain facial muscles, gets an interpreter to the way the expressing subject specifies her own behavior, if she does. At the very least, it yields a view of that behavior as a target of a subject's distinctive awareness. Either way, the interpreter has made contact with the subject's take on some aspect of the expressive whole. And that take can be used to guide how we specify the other main aspect of that whole - the expressed state. It helps guide us to a specification of the expressing subject's state on which it will be clear that she is in a determinate state, and clear that the state is cognitively significant.

This does not prove that the only proper way to respect expressed-dependence (and the introspectibility requirement) is to be guided by expressing behavior. But it does show that the simplest way to develop the modified account relies on such guidance, to a degree that secures expressing-dependence. So the modified version of Green's account, on the simplest plan for its development, fits the template. Recapping what drove the modification will show the significance of this.

Green counts urges-like the urge to injure-as characteristic components of common emotions. But his design requirement rules out, as not expressive, some actions that immediately satisfy such urges. Rejecting the design requirement, and declining to re-introduce the intention-to-express requirement, left us in search of another way to rule out, as non-expressive, such showings of emotional states as galvanic skin responses. The requirement that expressive activity be first-personally accessible was introduced as an alternative. As a result, expressing-dependence turns out to cover even non-linguistic expressions. (Expressed-dependence follows easily from the account's reliance on characteristic components and conventions.)

Of course, some yet-to-be-developed account could fail to fit the template while managing to treat hair-snuffling and crouching, but not galvanic skin changes, as expressive. Nothing argued here rules out that possibility. But Bar-On and Green have demonstrated how much can be accomplished by treating expression as showing. That makes some version of that treatment look like our best bet for a positive account. Any version of that account will need to sort expressive from non-expressive showings. Using the design requirement to do so excludes too many behaviors that enable perception of emotions. Substituting the first-person accessibility requirement on expressive behavior, however, results in an account that fits the template. So if we modify the attractive account of expression as showing to fit our intuitions about caresses and crouches, we will have an account that fits the template.

\section{CONCLUSION}

Analogies of four connections distinctive of successful communication with demonstratives are found in cases of expression. In both cases, the connections serve to guarantee that the states and behaviors they connect are states and behaviors of persons. We avoid mystification because we can trace out the specific roles expressing-dependence and expressed-dependence play in our interpretation of individual expressive behaviors. And we avoid behaviorism. While there may be 
reference-level connections between expressed states and expressive behavior in some particular cases, the connections at issue in the template are sense-level. They concern what is needed to interpret our fellows as in determinate states, doing determinate things.

Both the general template and the modified account of expression-as-showing, put forward in response to Green, rely on the notion of personhood. The template makes use of the idea of person-level engagement, of approaches to others that depend on viewing them as capable of rational motivation. And the modified version of Green's account implicates personhood in two ways. The introspection requirement for expressed states presumes some account of the distinction between introspection and other ways of knowing of an individual's states. And the firstperson accessibility requirement presumes we can distinguish various ways of knowing of one's own behavior, and single out those ways that no one but oneself can use. Accepting the template does mean there will be a somewhat tight circle between analyses of expression and analyses of personhood.

But this regiments, and helps explain, facts on the ground. Analyses of expression and of first-person authority already take in each other's washing. Green appeals to introspection in accounting for person-level expression (as opposed to artistic expressivity). Finkelstein appeals to expression in accounting for first-person authority and the distinction between conscious and unconscious mental states. Bar-On appeals to expression to account for the secure status of some self-ascriptions. And she appeals to the claim that expression is a kind of showing to explain which selfascriptions count as secure. Bar-On apparently comes closest to breaking out of the circle. She suggests that expressive behavior is sufficient to show what it expresses, and that this sufficiency requirement can't be met for states whose presence in a subject depends on facts beyond her control. Attention to sufficiency might let us pick out exactly the states we usually use 'introspectible' or 'occurrently conscious' to pick out, without relying on either notion. The account of expression could perhaps then proceed without any reliance on first-person authority. But there are two problems with this. One is that such an approach excludes states we might wish to count as expressible, such as perceptual experience and knowledge. ${ }^{63}$ The other is that pursuing the sufficient-to-show line requires treating all expressive behavior as a characteristic component of what it expresses. ${ }^{64}$ As I've argued, that requires appeal to a kind of unity between expressed states and expressive behavior. That unity will be most easily secured when a subject's own perspective on her states and behaviors is foregrounded in any account of either. But the relevant sense of 'own' will bring back appeals to the distinctively first-personal.

None of this means that only negative accounts of expression are possible. But it suggests that positive accounts of expression will depend on accounts of distinctively first-personal modes of self-awareness. That shouldn't be surprising. The concept of the expressive enables us to track the distinction between engaging with someone and merely coping with her, however competently and in interpretively sophisticated ways. And it is in our dealings with persons where we take this distinction 
to be serious. Persons expect to be engaged with and not merely managed. Such engagement requires the fit between the perspectives of expressing subject and interpreting audience that the connections laid out in the template would secure. ${ }^{65}$

\section{ENDNOTES}

1. Dummett 1981, especially chapter 3, "Was Frege a Philosopher of Language?" and 1991; Finkelstein 2003; and Bar-On 2004.

2. Bar-On 2004: 253 and 257-258. Bar-On is developing Gareth Evans's (1982) account of immunity to error through misidentification, which itself expands on Sydney Shoemaker's (1968) development of Wittgenstein's distinction between different uses of 'I' (1958b).

3. Positions sympathetic to this worry play a role in the on-going debate over whether Wittgenstein's notion of criterial connections helps illuminate expression.

4. The worry about a reductive form of behaviorism will be discussed in more detail below, in connection with Bar-On's concern to avoid certain behaviorist commitments. She is wary of any behaviorist commitment that would lead, in her view, to "an implausibly irrealist position in the philosophy of mind" $(2004,422)$. Of course, if its commitments were minimal, a non-reductive behaviorism might resemble, rather than threaten, some accounts of expression. Consider, for example, the commitments to avoiding metaphysical dualism and to allowing observed behavior to warrant third-person ascriptions of mental states. (Graham 2008 identifies minimal behaviorism with the adoption of just these two commitments.)

5. The interplay between conceptual and empirical questions will be discussed in more detail below, when considering Mitchell Green's positive account of expression.

6. Jennifer Hornsby (2000) argues that this is how we should understand Dennett's original distinction between the personal and sub-personal. Hornsby holds that person-level explanation is distinctive for its construal of persons as agents whose motives are rationally assessable, and that this construal requires finding a pattern of distinctive intelligibility in their actions and reactions. One talks about someone at the person level by foregrounding the fact that she is a person. Not everything one says about her at that level will concern her voluntary actions. Her perceptual experiences and her beliefs are other examples of states properly accessed at the person level (see also Hornsby 1997). (For discussion of this with respect to perceptual experience, see McDowell 1998c.)

7. I will focus primarily on perceptually based demonstrative reference, a sub-class of demonstrative, and that of singular, reference. Some, but not all, of what I say would apply to the larger classes.

8. The argument of this paper relies on, but does not independently defend, the way of thinking of demonstrative reference and communication involving it that is laid out in Evans 1982. See Campbell 2002 and 2006 for another articulation of, and reliance on, this view of communication with demonstratives. The success of such projects could provide both motivation and material for rigorous defenses of this view of demonstrative communication.

9. See Dummett 1981, 227 and Frege 1997, 156 on a word having a referent and expressing a sense. 
10. Certainly, some kind of understanding can be achieved even when complete communicative success is not. And this is true even in some cases of demonstrative reference where the hearer does not know to what the speaker has referred. A common way of regimenting what goes on in these cases is to distinguish (following Kaplan 1989) between the character and content of demonstratives. Gareth Evans, on whose work I'm drawing, objected to this sort of regimentation $(1985,302-306)$. The distinction between 'understanding' and 'full understanding' allows me to track the cases I'm interested in without requiring me to defend either Evans's view that all demonstrative sense is object-dependent, or his view that without such sense, there is nothing to understand in such cases. See Grush 2007 for useful explication.

11. The specific sensory modality by which she does so is not necessarily relevant, though it might be in some contexts. What is definitely ruled out is the use of a descriptive means of singling out Jane.

12. The relevant notion of possibility may be thin. For example, suppose that just as I utter my remark, Jane disappears down a tunnel slide, and we are forced to leave the playground before she emerges. My friend will not have the opportunity to understand my remark. But my utterance was understandable. And I believed its content.

13. On many theories of reference, the existence of the referent, while necessary to referential success, won't be sufficient for success. For Evans, for example, the sense of the referring phrase must also provide the speaker with an identification of the referent (1982, 170-179).

14. Here too there will be cases where some understanding is achieved even by hearers who fail to appreciate fully what a speaker did. Perhaps they miss the illocutionary force of an utterance, or haven't kept track of a conversational implication that is crucial to communication in this context. But whatever understanding they achieve won't be the full understanding at issue in communicative success.

\section{Compare Evans 1982, 71.}

16. I'm assuming that content in general, and so that portion of a believed-content expressed with a demonstrative, is essentially tied to subjectivity. That is, content is essentially such as to be enjoyed by subjects, and not by, e.g., sub-personal parts of subjects. See McDowell 1998a and Searle 1983. I would argue that Stich 1978 is making the same point.

17. The relations must be similar enough that each by itself can, in the context, provide the agent relating to Jane with the capacity to identify Jane demonstratively. In some contexts, it might be that a speaker and hearer using different perceptual modalities to perceive Jane nevertheless manage to have similar enough identifications of her for them to achieve full communicative success.

18. See, for example, the opening sections of Perry 2001. Perry is laying out different theories of reference. His botanization betrays his assumption that any identification of an object that is graspable in thought must be descriptive.

19. I'm borrowing the terminology, and the explanation of the distinction, from Brandom 2002, 194-199.

20. For something closer to reference-level dependence, see the discussions below of BarOn's and Green's suggestion that some expressive behaviors are characteristic components of the mental states they express.

21. See Part I of Cavell 1979, which focuses mostly on Wittgenstein 1958a. 
22. This is compatible with the possibility that on some occasions, a mental state like sorrow could be the cause of its expression in a more robust sense. And it is also compatible with the possibility that an actress in a play with a funeral scene could weep without feeling any sorrow herself. Finally, note that Green explicitly allows that an emotion may cause the facial movements and behavioral dispositions that (on his view) partially constitute it $(2007,90)$.

23. The discussion here has been influenced by Bar-On's handling of the relation between two distinctions $(2004,248-250)$. The first distinction is between rational and brute causation. The second is between a person expressing her state via an intentional action and a behavior expressing the state that causes it. Bar-On's project doesn't require her to find any positive similarity between these two kinds of expression. All she needs is a negative similarity: that in neither case is the expressive behavior dependent on the subject making an identification of what is expressed. She thinks it likely, however, that there are positive similarities.

24. For this expanded sense of the voluntary, as outrunning that which is preceded by a conscious decision, or that which can be done at will, see Bar-On 2004, 249 and Green 2007, 28 and 122. Bar-On appears to treat as voluntary any of one's behaviors one can modulate, while Green requires us to be able to prevent a behavior at its time of onset in order to call it voluntary. (This difference may not be significant, because there isn't a bright line between complete prevention and modulation to the point of rapid suppression.) What behaviors are voluntary even in this expanded sense varies from person to person. The variation is sensitive to cultural influences. And we can over- and under-estimate the degree to which certain behaviors are voluntary for us in this sense.

25. Mitchell Green might look like an apparent exception. I will discuss the connection between his account of expression and the idea of rational causation below.

26. How to treat behaviors that have causal relations to mental states, are not cognitively significant to their subjects, and are of questionable expressive status, is discussed below in connection with Green's account.

27. Bar-On rejects any approach that makes one's expression of a state wholly or partially constitutive of being in that state. I focus on one reason-her desire to preserve expressive status for actors' behaviors. But she also finds such approaches inapplicable to many phenomenal states and their avowals, and problematic for our accounts of the mental lives of human infants and some non-human animals. These last concerns pertain to accounts of self-knowledge that locate constitutive connections between "the nature and presence of firstorder mental states and the presence of correct self-ascriptive judgments" (Bar-On 2009, 60). According to Bar-On, a subject's self-ascription, whether uttered audibly or not, counts as an expression. So these accounts of self-knowledge, while obviously not behaviorist, also make the constitutive links between mental states and their expressions that Bar-On rules out.

28. The quotation is from a paragraph in which Bar-On is endorsing disjunctivism and comparing her view of avowals' warrants to the views laid out in McDowell 1998b. Disjunctivism about perceptual states plays a large role in McDowell 1996.

29. Bar-On 2004, 395; emphasis original. See also p. 403.

30. This may seem tendentious. Certainly, a behavior will need to be subject to assessment for (un)reasonableness in order to count as an act, but it need not in fact be reasonable. But in the passage on p. 395, Bar-On appears to mean 'reasonable' in the following sense: one could think of interpretations on which we would not have to condemn the agent of 
irrationality. And that is quite close to the sense of 'rationally assessable' needed to distinguish acts from mere behaviors. A further clarification: the following paragraphs argue that Bar-On is committed to expressed-dependence. Following Bar-On, they focus on behaviors that are clearly voluntary (avowals, but also exclamations like, "That hurts!"). Discussion of expressed-dependence for behaviors whose voluntary status is more equivocal comes in the next section, and in the section below devoted to Green's account.

31. So when it is put in appropriate form, the particular sense-level connection that Bar-On allows between expressings and expressed states amounts to expressed-dependence. When this is highlighted, we see an example of a very strong conceptual connection that is nevertheless distinct from the constitutive conceptual connections Bar-On rejects. We also see that Bar-On's claim that her account makes only one kind of connection between mental states and expressive behavior is not correct (2004, 422; the passage is quoted and discussed in the next section.)

32. See Davidson 1984. Bar-On remains agnostic on the point, but argues that her account doesn't require her to insist that beliefs have non-linguistic expressions. All that matters is that they have non-self-ascriptive expressions, which can be replaced by avowals (at least some of the time, by the "seasoned speaker") $(2004,294)$.

33. Again, it matters that this is a sense-level connection. David Finkelstein's (2003) claim that expressions contextualize, and so partially constitute, expressed states, is perhaps a reference-level version of expressing-dependence. In generalizing expressing-dependence (in the remainder of this section and the next), I am continuing to construe it as a senselevel relation. If the characteristic component accounts I will discuss below are true, then there are also reference-level expressing-dependencies. If so, those would be reference-level dependencies that weren't constitutive dependencies.

34. Bar-On distinguishes non-expressive from expressive showings by arguing that the latter are sufficient to show what they express. For the purposes of comparing Bar-On and Green, it could be useful to think of Bar-On's notion of 'sufficient to show' as matching Green's notion of 'showing,' and often his notion of perception-enabling showing. What Bar-On labels 'showing' — such as my drawing up a sleeve to reveal the skin that shows my sunburn-could perhaps be thought of as 'helps to show.'

35. Note that this formulation doesn't clearly rule out the possibility that the expressive behavior has a tight sense-level connection to the concept of that particular mental state.

36. Green proposes the following usage for 'characteristic component': "Let $\alpha$ be an object, event, or process that is perceptible. Then we may say that relative to an organism $\mathrm{O}$ and ecological situation $\mathrm{E}$, a characteristic component of $\alpha$ is a part of $\alpha$ that, when perceived in E without any other part of $\alpha$ being perceived, enables $O$ to perceive $\alpha$ " (87). Making characteristic component status relative to both observers and environments fits with Green's inferentialist account of perception. A side of an apple is a characteristic component of an apple for a normal human perceiver in, say, a grocery store. Green claims that this "amounts to the fact that under normal conditions, perception of part of an apple's surface is enough to justify [such a perceiver] in inferring (if only unconsciously) the existence of the entire apple" (86). But perceiving a one-micron-square segment of a skyscraper would not justify a normal human perceiver in inferring the existence of the building, so such segments are not characteristic components of skyscrapers for us. Like Bar-On, Green emphasizes that characteristic components can be conventional or atypical components. But he doesn't give 
a general account of what unifies components. Hence what justifies perceivers' inferences remains unexplored.

37. Green distinguishes perception-enabling showings of objects or states from (nonperceptual) showings-that something is the case, and showings-how something feels. Each kind of showing enables knowledge of what it shows.

38. Bar-On would agree that one cannot express what cannot be introspected. But she can't rely on that point to delineate the scope of the expressive, because she's trying to explicate self-knowledge in terms of expression. Such a stipulation would reverse her order of explanation.

39. I'm paraphrasing the definition of 'signal' provided in the Appendix (Green 2007, 212).

40. Green notes that "our commonsense patterns of thought and description of one another" count emotions as perceptible $(2007,91)$. He argues that we may follow the common view, as it is not incoherent (90-92). Treating emotions as perceptible allows him to consider what characteristic components might enable their perception.

41. I've lightly modified a case presented in Green 2007, 93.

42. Green notes that someone might hug a friend, aiming to display her care to that friend, but might also do so with no such aim in mind $(2007,33)$. And the same applies to "cases in which the target of one's expression [e.g., a photograph one kisses] stands in as a prop for the object of one's expressed state" (43).

43. Green presents a case where an angry person only makes as if to injure the target of her anger, by mutilating a photograph $(2007,37)$. And the explanation for why this counts as behavior designed to show is that "attacking something associated with an object of rage is a widely used signal of that rage" (ibid.). In another case where Green discusses making-as-if to satisfy an urge, he discusses making a shooting gesture at a colleague. And this gesture can show one's annoyance, he says, because it partially satisfies the urge to injure which is a characteristic component of that emotion, a (mild) species of anger. He classes this as a case of expressing without explaining how the design requirement is satisfied. (Of course, if the person making the gesture intended it to show her anger, the design requirement is satisfied. But Green emphasizes that urge-satisfying actions may be done for no other reason than the satisfaction they provide.) I am assuming that attacking the target of one's anger, and not only something affiliated with that target, could be a signal of anger. If Green would deny this, the case I present below is only strengthened. It isn't a point in favor of his view if it can't count direct attacks on others as expressions of anger at them.

44. See also Green 2008, 393; 2009, 145n9.

45. Here is the concern about over-broadening the category of expression. Without some careful work on what counts as satisfying an urge, almost any action provoked by an urge might come to count as expressive. But while a slap is typically counted as expressive of anger, mailing an anthrax-laced letter in delayed retaliation for a slight is not. Yet both satisfy the urge to injure, and both count as designed, if I am right that Green would count actual attacks on objects of rage as signals of rage (see note 43 above). So both count as expressive for Green.

46. Green implies the link when he first presents the design requirement in his 2007 book, but this paper makes clear that he does mean to be talking about our ordinary concept of expression. He's not making a point that would apply only to a philosopher's cleaned-up 
version of it. Of course, he takes it that common sense is correct. The link between expressivity and design isn't, in his view, simply created by our common view of expression.

47. As discussed above, when an urge is a characteristic component of a mental state, I take an act that directly satisfies that urge to express that state, regardless of whether the agent of that action intended it to do so. Therefore, like Bar-On and Green, I too must reject an intention requirement on expression. For this reason, I reject Wayne Davis's analysis of expression, which makes the intention to indicate one's mental state necessary to expression (see Davis 2003, chap 3; 2008a, 117-118; 2008b, 427-428). For more general arguments against this portion of Davis's account of expression, see Green 2008. (Green also argues that indication is not sufficient for expression.) Note 59 below discusses Davis's responses (2008a and 2008b) to Green's criticisms.

48. I'm only discussing how the design-requirement works to whittle the perception-enabling showings down to the expressive ones. In principle, the design-requirement also delineates expressive showings-that and showings-how. But it will be less obvious that there are actual cases of agents showing their states in one of these ways without thereby expressing them. As discussed below, on Green's own account, showing is often accomplished in these cases only by design.

49. For a sample of the active debate on this topic, see Dijk, de Jong, and Peters 2009, arguing that blushing is a signal, and Crozier 2004 articulating uncertainty about its signal status (while making a number of assumptions about the role of facial signals (such as their needing to be producible at will) that Green would dispute).

50. I'm assuming only that there is some such way, and that it is distinctively first-personal. Of course, that there is anything significant distinguishing first-personal and third-personal relations to one's body, mental states, and actions is a serious assumption. But it is no more serious than the assumption Green makes in limiting expressible states to introspectible states. After all, introspection is only distinctive enough to do this limiting work if it is (in some way) distinctively first-personal. I'm suggesting Green broaden his introspectibility requirement, and use that broader notion of distinctive first-personality to limit not only what can be expressed but what can do expressive work. Embracing either requirement means incurring a commitment to give up expressive/expressing status for any state or behavior that turned out, on our eventual best theory of the first-personal, not to be knowable first-personally.

51. And one might be aware of some behavior, but not yet be aware of it as expressing what it does.

52. The template under consideration in this paper has immediate application only to accounts of self-expression, or attempts at it, in Green's sense of 'self-expression.'

53. Green argues that speech acts can show that speakers have (for example) beliefs and intentions. Speech-acts signal the presence of such states in a way that makes a speaker liable to severe penalties if she does not in fact have the state she signals. (In making a speech act, one incurs certain (conventionally dictated) commitments, and risks losing credibility in the community if one fails to live up to them [Green 2007, 70-73; 2009, 152-155].) Green argues generally that handicaps - signals that are very costly to produce-show what they signal. On his handicap theory of speech acts, then, our speech acts express what they do because of how they signal what they do. In this case, designed-status is not a way of achieving expressivity after showing is achieved. The signaling is how the showing can be accomplished at all. 
54. Both of the models Green explores for counting showing-how as (knowledge-enabling) showing, and not mere indicating, also turn out to involve showing that is achieved via signaling (see the previous note) $(2007,186)$.

55. See de Gelder et al. 2004, finding that study subjects could perceive postures as fearful even when the faces of individuals in the target images were blanked out. And, while this is hardly decisive, it is interesting that de Gelder and colleagues call these postures "wholebody expressions" of fear (16701, emphasis added). Green could allow that they show fear, but not that they express it-unless they all turned out to be signals of fear.

56. De Gelder and her colleagues found that subjects viewing fearful postures (as opposed to meaningful but emotionally neutral postures) had elevated activity in brain regions known to process emotional information, as well in regions "dedicated to action representation and in motor areas" $(2004,16702)$. They speculate that fear-perception may lead to fear-contagion, and perhaps to appropriate action-preparation (16705). Mechanisms for perceiving postures as fearful, and for generating appropriate responses, could be designed independently of the signal status of the postures.

57. One might begin to back up the socialization point by drawing on recent work on folkpsychology. A number of theorists are now arguing that folk-psychology plays a large role in shaping us: it helps us hold one another to certain standards of cognitive and affective behavior, and increases individuals' capacity to hold themselves to those standards. (See, for example, McGeer and Pettit 2002; McGeer 2007, and Zawidzki 2008). Being thus shaped, and getting good at continuing the shaping, might depend on basic abilities to perceive others' behavior as expressing what it does. And those abilities could get stronger, and expand to cover more kinds of behavior, over time.

58. Beyond recognition, Green might say. But I submit that the commonality most fundamental to his account is that all expression is showing and hence (for relevant observers) knowledge-enabling (see Green 2009, 143). Design is how behaviors that don't initially appear capable of showing (rather than merely indicating) manage to show what they do.

59. Davis holds that a subject can express her mental state only with an action she intends as an indication of that state. Subjects can't express their states with actions that aren't intended as indications, and they can't express their states with actions that aren't intended at all $(2008 \mathrm{a}, 117-118 ; 2008 \mathrm{~b}, 427)$. Non-intended behaviors can express mental states in an evidential sense, but the subject whose behaviors they are is not expressing herself thereby. Davis argues that Green's account of expression improperly treats some cases where a behavior evidentially expressed a state as cases where a subject expressed her state (via that behavior). Someone who thought expression was paradigmatically a personlevel phenomenon might think she had to accept Davis's criticisms of Green. The variety of ways of meeting the person-level requirement just discussed could help persuade her otherwise. Self-expression does have to be person-level, but that can be secured even if a stretch of expressive behavior is not voluntary. The first-person accessibility requirement links expressing behavior and subject. With that link in place, Davis's distinction between speaker expression and evidential (merely behavioral) expression appears both misplaced and too rigid.

60. Recall that this is a sense-level requirement. It will still be possible for a good actress to cry without feeling sorrow herself. (Of course, Green won't count that as a case of selfexpression.) 
61. Because the connections are sense-level, the state expressed isn't expanded to include the content of the convention. So nothing here implies that speakers who express states by means of illocutionary acts must be self-consciously following the conventions in question.

62. Thus, Green clarifies his requirement as follows: "What is required for expressibility is that the state in question fall into some category such that states in that category can in general be known by introspection" $(2007,39$ n11).

63. Whether such states are expressible is controversial, of course. (Green's account would allow us to express them by showing-that we had them.) Bar-On explicitly denies that perceptual experiences - that is, seeings of trees and hearings of crickets-are expressible. For arguments that many other mental states have success conditions beyond a subject's control, and hence can't be self-ascribed in avowing mode (on Bar-On's account), see Tanney 2007.

64. Since Green denies that all expression is perception-enabling, he would not accept this method of breaking out of the circle.

65. A very early version of this paper was presented at the Expression Workshop held at Georgetown University on May 11, 2007, and I benefited from discussion with the audience and my fellow presenters (Dorit Bar-On, Wayne Davis, Mitchell Green, and Stephen Gross). A later version was presented at a Colgate University Philosophy Department work-in-progress reading group, and my colleagues offered insightful criticisms. Mark Jenkins provided very useful comments on a draft. I am especially grateful for the substantial and detailed feedback provided by an anonymous referee for this journal. Some of the work on this paper was made possible by a Junior Faculty Leave granted by Colgate University.

\section{BIBLIOGRAPHY}

Bar-On, Dorit. 2004. Speaking My Mind: Expression and Self-Knowledge. New York: Oxford University Press.

- 2009. "First-Person Authority: Dualism, Constitutivism, and Neo-Expressivism." Erkenntnis 71: 53-71.

Brandom, Robert. 2002. Tales of the Mighty Dead: Historical Essays in the Metaphysics of Intentionality. Cambridge, MA: Harvard University Press.

Campbell, John. 2002. Reference and Consciousness. Oxford: Clarendon Press. . 2006. "What is the Role of Location in the Sense of a Visual Demonstrative? Reply to Matthen." Philosophical Studies 127: 239-254.

Cavell, Stanley. 1979. The Claim of Reason: Wittgenstein, Skepticism, Morality and Tragedy. New York: Oxford University Press.

Crozier, W. Ray. 2004. "Self-Consciousness, Exposure, and the Blush.” Journal for the Theory of Social Behavior 34: 1-17.

Davidson, Donald. 1984. "Thought and Talk." In his Inquiries into Truth and Interpretation. Oxford: Clarendon Press, 155-170.

Davis, Wayne A. 2003. Meaning, Expression, and Thought. New York: Cambridge University Press. 
—. 2008a. "Expressing, Meaning, Showing, and Intending to Indicate." Intercultural Pragmatics 5: 111-129.

- 2008b. "Reply to Green." Philosophical Studies 137: 427-432.

De Gelder, Beatrice, Josh Snyder, Doug Greve, George Gerard, and Nouchine Hadjikhani. 2004. "Fear Fosters Flight: A Mechanism for Fear Contagion When Perceiving Emotion Expressed by a Whole Body." Proceedings of the National Academy of Sciences 101: 16701-16706.

Dijk, Corine, Peter J. de Jong, and Madelon L. Peters. 2009. "The Remedial Value of Blushing in the Context of Transgressions and Mishaps." Emotion 9: 287-291.

Dummett, Michael. 1981. Frege: Philosophy of Language. 2d ed. Cambridge, MA: Harvard University Press.

_ 1991. "The Relative Priority of Thought and Language." In Dummett, Frege and Other Philosophers. Oxford: Clarendon Press, 315-324.

Evans, Gareth. 1982. The Varieties of Reference. Ed. John McDowell. Oxford: Clarendon Press.

1985. "Understanding Demonstratives." In his Collected Papers. Oxford: Clarendon Press, 291-321.

Finkelstein, David H. 2003. Expression and the Inner. Cambridge, MA: Harvard University Press.

Frege, Gottlob. 1997. “On Sinn and Bedeutung.” In The Frege Reader, ed. Michael Beaney. Oxford: Blackwell.

Graham, George. 2008. "Behaviorism.” In The Stanford Encyclopedia of Philosophy (Fall 2008 edition), ed. Edward N. Zalta. URL = http://plato.stanford.edu/archives/fall2008/ entries/behaviorism.

Green, Mitchell S. 2007. Self-Expression. New York: Oxford University Press.

. 2008. "Expression, Indication, and Showing What's Within." Philosophical Studies 137: 389-398.

—. 2009. "Speech Acts, the Handicap Principle, and the Expression of Psychological States." Mind and Language 24: 139-163.

Grush, Rick. 2007. "Evans on Identification Freedom.” Canadian Journal of Philosophy 37: 605-617.

Hornsby, Jennifer. 1997. Simple Mindedness: In Defense of Naïve Naturalism in the Philosophy of Mind. Cambridge, MA: Harvard University Press.

_ 2000. "Personal and Sub-Personal: a Defence of Dennett's Original Distinction." Philosophical Explorations 3: 6-24.

Kaplan, David. 1989. "Demonstratives.” In Themes from Kaplan, ed. Joseph Almog, John Perry, and Howard K. Wettstein. New York: Oxford University Press, 481-563.

McDowell, John. 1996. Mind and World. 2d ed. Cambridge, MA: Harvard University Press. 1998a. "Intentionality De Re." In his Meaning, Knowledge, and Reality. Cambridge, MA: Harvard University Press, 260-274.

1998b. "Knowledge and the Internal." In his Meaning, Knowledge, and Reality. Cambridge, MA: Harvard University Press, 395-413.

_. 1998c. "The Content of Perceptual Experience." In his Mind, Value, and Reality. Cambridge, MA: Harvard University Press, 341-358. 
McGeer, Victoria. 2007. “The Regulative Dimension of Folk Psychology.” In Folk-Psychology Re-Assessed, ed. Daniel D. Hutto and Matthew Ratcliff. Dordrecht: Springer, 137-156.

McGeer, Victoria, and Philip Pettit. 2002. "The Self-Regulating Mind." Language and Communication 22: 281-299.

Perry, John. 2001. Reference and Reflexivity. Stanford: CSLI Publications.

Schulte, Joachim. 1993. Experience and Expression: Wittgenstein's Philosophy of Psychology. Oxford: Clarendon Press.

Searle, John. 1983. Intentionality. Cambridge: Cambridge University Press.

Shoemaker, Sydney. 1968. "Self-Reference and Self-Awareness." Journal of Philosophy 65: 555-567.

Stich, Stephen P. 1978. "Beliefs and Subdoxastic States.” Philosophy of Science 45: 499-518. Tanney, Julia. 2007. "Review of Speaking My Mind, by Dorit Bar-On.” Mind 116: 727-732. Wittgenstein, Ludwig. 1958a. Philosophical Investigations. 3d ed. Trans. G. E. M. Anscombe. New York: Macmillan.

1958b. The Blue and Brown Books. New York: Harper and Row.

Zawidzki, Tadeusz W. 2008. "The Function of Folk-Psychology: Mind Reading or Mind Shaping?” Philosophical Explorations 11: 193-210. 